\title{
Trans experiences of a university campus in northern England
}

Accepted for publication in Area. The information, practices and views in this article are those of the

authors and do not necessarily reflect the opinion of the Royal Geographical Society (with IBG).

\section{Authors:}

Graeme W. Mearns - corresponding author

Geography, Politics and Sociology, Newcastle University, Newcastle, UK

Email: graeme.mearns@ncl.ac.uk

Carl Bonner-Thompson

School of Geography and Environment, University of Oxford, Oxford, UK

\section{Peter Hopkins}

School of Geography, Politics and Sociology, Newcastle University, Newcastle, UK

Article type: Regular paper

Abstract: The spatial experiences of transgender and gender non-conforming ('trans') people continue to occupy the margins of geography, especially compared to the amount of work centred on lesbian and gay lives. Though research on trans geographies in educational and health settings is expanding, most literatures stem from the U.S. This article shares findings from a study about the experiences of trans people who study and/or work on a specific university campus in northern England. Our findings demonstrate how particular spaces of the campus are generative of interactions which enable microaggressions and misrecognition.

Funding information: There are no funders to report for this submission

This article has been accepted for publication and undergone full peer review but has not been through the copyediting, typesetting, pagination and proofreading process, which may lead to differences between this version and the Version of Record. Please cite this article as doi: 10.1111/AREA.12595

This article is protected by copyright. All rights reserved 
Data availability statement: Data cannot be shared for ethical reasons

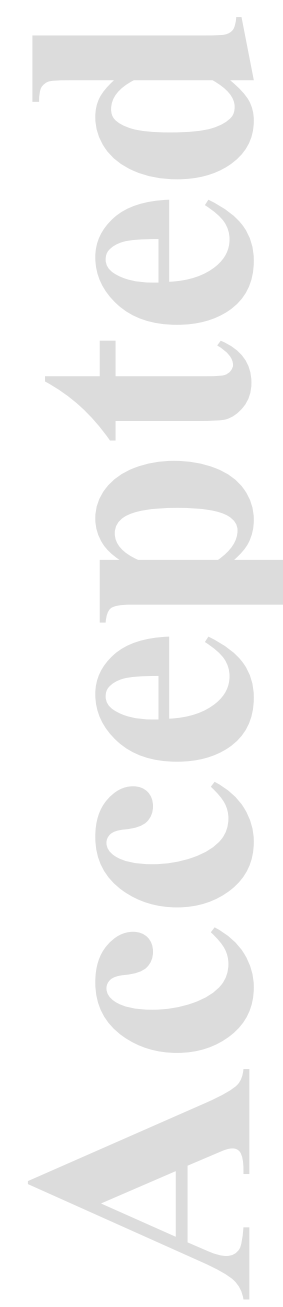

This article is protected by copyright. All rights reserved 
Article type : Regular Paper

\section{INTRODUCTION}

In this article, we explore the experiences of transgender staff and students on a university campus in northern England. University campuses are sites of meaningful encounters (Andersson et al. 2012) and those who identify as transgender and/or gender non-conforming are some of the most marginalised students on campus. We contend that it is important to give voice to the experiences of transgender staff and students and we set out to do so in this article.

We offer a brief introduction to debates about transgender geographies before setting out the Foucauldian and queer perspectives framing our research. We then detail findings according to the three spaces in which trans students and staff felt most marginal: bathrooms, residential accommodation and spaces of learning and conviviality. A final part of the article summarises how campuses may be made inclusive of trans people.

\section{TRANS GEOGRPHIES OF THE CAMPUS}

British anti-discrimination laws have only been extended to trans people during the past decade, partly thanks to Press For Change and similar advocacy groups (Mitchell and Howarth, 2009). There remains no Census data on the trans population in England, Wales and Scotland but estimates suggest there are anything from 65,000-300,000 trans people in the UK. A 2014 survey of 4000 lesbian, gay, bisexual and trans (LGBT) students by the National Union of Students highlighted that only $20.6 \%$ felt 'completely safe' on campus whilst a third had suffered bullying and 56\% considered 'dropping out' (Acciari, 2014). In June 2019, the Metropolitan Police confirmed a doubling of hate crimes against LGBT people in the past five years in wider society (Marsh et al. 2019).

Historically, universities have been seen to provide people with an opportunity to experiment with alternative gender and/or sexual identities away from constraints of 'home' and school (Marine and Nicolazzo, 2014). However, Formby (2015) posits that there remain 
few qualitative studies that detail the specific challenges faced by trans students and staff in the UK. Research on trans lives is usually U.S-centred (Ullman, 2018) or situated alongside 'sexual minorities' (Ellis, 2008). This article contributes to addressing this imbalance by using constructionist/Foucauldian and queer perspectives to explore how trans lives are lived out on campus, focusing on three specific spaces where micro-aggressions and misrecognition are experienced. Misrecognition is about the ways which individuals are misidentified leading to them being denied the "denied the status of a full partner in social interactions, as a consequence of institutionalized patterns of cultural value that constitute one as comparatively unworthy of respect or esteem" (Fraser 2000, 113-14, see also Hopkins et al, 2017). These processes are spatially reproduced (Foucault, 1977) and operate to generate structures of surveillance and to normalise social systems such as that identified by Doan (2010: 635) as the 'tyranny of gender':

The exercise of power which is cruelly or harshly administered [when] trans and gender variant people experience the gendered division of space as a special kind of tyranny that arises when people dare to challenge the hegemonic expectations for appropriately gendered behaviour in western society. The gendered expectations are artefact of the patriarchal dichotomisation of gender and have profound and painful consequences for many individuals. [...] The tyranny of gender intrudes on every aspect of the spaces in which we live and constrains the behaviour that we display.

Namaste's (1996) critique of 'gaybashing' was one of the earliest works in geography to account for the impacts of the gendered division in the context of urban LGBT space. This research showed how the male/female binary differentially disciplines the embodied lives of lesbians and gay men whilst erasing or denying recognition of trans people (see, also, Namaste, 2000; Stryker, 2006; Stryker and Whittle, 2009). Ghaziani (2008) observes a premise of trans people as 'invading [LGBT] community spaces and [being] rendered different by virtue of their lack of adherence to the gender dichotomy' (in Waling and Roffee, 2017: 305). In other words, whilst many LGB people support inclusion of diverse queer identities, others can feel threatened by the presence of identities and bodies that do not adhere to normative gender scripts. Abiding to a modified heteronormative approach allows many lesbians and gay men to render identities 'normal' in a society that actively works to disempower them (Duggan, 2003; Oswin, 2008).

Appreciating how the tyranny of gender can penetrate LGBT spaces is useful in light of the hostile terrain of trans politics external to queer lives such as lasting biphobia, 
homophobia and transphobia that can still wield damage on even the most 'normal' queer lives (Brown, 2012). This is one of the reasons that Browne (2004) proposed the term 'genderism' to illustrate the hostilities faced by trans people in sex-segregated bathrooms; arguably, the spaces that have resulted in some of the most heated public debate in respects of trans rights (Anthony and Dufresne, 2007; Herman, 2013; Jeffreys, 2014). Browne's (2003) work exemplifies the different kinds of microaggressions trans people are confronted with the frequent treatment or actions, verbal, behavioural or environmental, that can shame individuals by conveying hostile, derogatory or otherwise prejudiced attitudes (Sue, 2010). Micro-aggressions and misrecognition are interlinked and both work in combination to bolster the tyranny of gender.

Whilst constructionist approaches (including those of queer theory) have been critiqued for sometimes using trans bodies to articulate the 'fluidity' of gender, Doan (2016) clarifies how a queer destabilising of gender (transcending the male/female gender binary) as socially constructed can be a powerful way of illuminating how the tyranny of gender unfolds in and through different spaces if trans bodies are not discounted - in analysis - from the environments in which they live, breathe and excrete fluids (see, also, Cornwell, 2014; Johnston, 2015; Rosenberg and Oswin, 2015). After detailing our methodology, we explain how three spaces of the campus enable micro-aggressions and misrecognition.

\subsection{The research}

Fifteen semi-structured interviews were conducted between March 2017 and June 2018 with academic and professional staff as well as postgraduate and undergraduate students who identify as transgender or gender non-conforming. Agender (1), female (2), trans female (2), female-aligned (1), trans men (3), non-binary (4) and gender non-conforming (2) people are represented. Participants identified as bisexual (4), gay (1), pansexual (5) and queer (5). All but two people identified as 'white-British or mixed white-British' whilst one 'British Pakistani' and one 'Chinese' persons also contributed. The participants were aged 18-33 years and interviews took place in private offices on campus or in nearby cafes. Interviews lasted between forty-five minutes to well over an hour.

Each of the authors conducted interviews. We are white, educated to postgraduate level and occupy a differing positions within the hierarchies of the academy. Whilst we are outsiders to the trans community, we are members of the LGBT community and so shared some similarities with our participants meaning This helped build rapport and made us, we argue, more sensitive to the gendered experiences shared with us in a way that might not have

This article is protected by copyright. All rights reserved 
been achievable if we did not share specific similarities with our participants. . We now focus on the three spaces of the campus: bathrooms; student accommodation; and teaching, learning and socialising places. We consider each of these in turn.

\section{BATHROOMS}

Bathrooms are often troubling for trans people as they usually reinforce the gender binary (Browne, 2006; Cavanagh, 2011; Overall, 2007; Penner, 2012). Extending Foucault's (2004) 'docile bodies' to gender, Bender-Baird (2016: 984) contend that sex-segregated bathrooms are 'not neutral but, rather, are where power is enacted'. She also suggests sex-segregated bathrooms act as technologies of disciplinary power that uphold the binary by funnelling people into men's or women's spaces through three kinds of disciplinary power: first, division of space into (gendered) functions; second, panoptic design that encourages surveillance; and third, production of docile, 'appropriately gendered' bodies. There is evidence of each kind of power in the experiences of participants who contributed to our study.

Access to all gender facilities is geographically uneven. In the examples that follow, we see their importance (toilets and changing rooms) with appropriate signage indicating the inappropriateness of challenging people about their bathroom presence based on perceived gender. The examples highlight how diverse trans identities and bathrooms are linked in complex ways according to how certain bodies occupy a given space:

It certainly is a lot easier being a binary trans person I think because that clearly signals I am in the right place. I mean [...] pre-transition, the facilities in my building were all gender neutral, all of them. Which was great...I didn't have to think about that every time.

(Hannah, 32 year old trans female)

As Hannah clarifies, limited access to all gender facilities works to force people into gendered spaces but as a non-binary person, they understand themselves as privileged in being able to 'fit' gendered expectations by appearance. Hannah often manages to use women's bathrooms without provoking suspicion. By contrast, both Rebecca and Alex detail discomfort:

There are disabled toilets everywhere but a lot of able-bodied trans and non-binary people feel awkward about using disabled toilets because technically, the label on it isn't for us because we're able-bodied. I mean, in the past, I have not had a problem at

This article is protected by copyright. All rights reserved 
all with using disabled toilets just because I know that sometimes I need a genderneutral space.

(Rebecca, 18 year old non-binary)

Yes, that's really recent and, like, I know in the student union there's like, the disabled toilet is like a gender-neutral toilet, I kind of feel guilty using it, I feel like, I don't want to walk outside and there's somebody actually disabled waiting to use the toilet... like, in my department, there's no neutral or anything. And, like, normally I don't feel bothered about it, but some days looking at the sign going in, it's like the worst thing ever.

(Alex, 29 year old queer non-binary)

Whilst Hannah's gender identity is stabilised in gendered bathrooms, the male/female designation still acts as a relentless reminder of the tyranny of gender. Furthermore, Rebecca and Alex highlight how a lack of all gender facilities can leave people in the difficult position of being viewed as negatively impacting others' needs; what Jake posited as a situation of 'elevating the needs of one minority by encroaching on the space of anothers. Simply labelling accessible toilets as gender-neutral does not create 'safe space' for trans bodies.

In short, we see the production of docile, 'appropriately gendered' bodies that BenderBaird (2016) refer to and an interrelated lack of access to all gender facilities. Both of these issues are daily realities for those living outside binary expectations. Confronted by a built environment that denies existence (and bathrooms facilitating policing), trans people can engage in situational docility, wherein bodies are adjusted to comply with gendered norms. We echo a need to transform bathrooms into all-gender spaces to mitigate need for situational docility.

\section{STUDENT ACCOMODATION}

Trans experiences of student accommodation (university-affiliated or private) were mixed. Self-surveillance and censorship were stressed as necessary within residential spaces and trans students often described a 'pot luck' process that determined the flatmates they ended up living with. Irrespective of whether or not flatmates were trans-aware, participants detailed heightened feelings of 'the gaze' in residential accommodation and reacted accordingly:

I just felt so hyper aware of my presentation... the way I spoke and the way that people were seeing me. Because I reckon most trans people agree, you kind of know when people are reading you as the correct gender or not even if they don't outwardly use the

This article is protected by copyright. All rights reserved 
wrong pronouns. You can just get this feeling. It's really hard to describe... but you just kind of know if people are reading you as male or female when you're speaking to them... the first few weeks, trying to work out if people... when I left the room... what pronouns were people going to be using and it was anxiety-inducing.

(Jake, 20 year old trans male)

Jake summarises the (hyper)awareness he felt in managing self presentation whilst living with new people. This hypervigilance requires a consistent preservation of gendered codes and behaviours. Anxiety was the main emotion felt in instances where a hostile gaze was experienced. Such feelings were described as 'being seen' only for their gender, feeling 'on show', or 'held representative' of all trans people; exacerbated in situations requiring movement to another address or at times of mixity with new flatmates:

It's like, I don't feel like a girl so being part of the girls is, like, really weird and I feel almost like I've disguised myself or something... I feel sneaky. I feel like I'm lying or something and also, it brings up a feeling like, when I said I was part of the LGBT society, I was worried that they would start thinking I was, like, going to perv on them or something. Like, they think you fancy everybody. So, I think there's, like, I don't know how to put it... So when they're trying to make you part of... like one of the girls, you feel like it's wrong and you feel like "No, you don't want me."

(Alex, 29 year old genderqueer)

Alex describes how he has participated in difficult conversations about the sensitive use of gendered language with flatmates. He also explains that because he is still usually treated as female, he has distanced himself from the friendship circle shared by his cisgender peers. Presence, within his residence - and interactions with flatmates who lack understanding of gender diversity - give rise to feelings of being untrue to oneself: as 'disguised', 'sneaky', 'lying'. He also articulates well-documented tropes of queerness being felt as perversion, a remnant of decades of prejudice levelled at gender and sexual minorities alike (Bell, 1995).

Further, accommodations guidance may be helpful in circumventing awkward situations in which a trans person feels unable to express their identity with those with whom they reside. Jane, a 26 year old trans female provides an example of one such scenario:

One of my flatmates was an extreme Christian and didn't appreciate me coming out and didn't really like me much. So she would deadname ['known as' name prior to 'coming out' and/or gendered transition] me a lot. I was not her fan but I just ignored her. I avoided her like the plague. [...] The other ones moved out eventually so it ended up This article is protected by copyright. All rights reserved 
being just me and her... We had a few disputes... not like very confrontational. Just passive aggressive. [But another...] of my flatmates - friends even - are incredibly supportive to the point where they had a little tea party when he got on $\mathrm{T}$ [testosterone] which is cute.

Jane highlights the 'passive aggressive' tension existing between herself and a flatmate after 'coming out' as trans but also clarifies the support of her peers which mirror what Andrucki and Kaplan (2018) describe in the context of trans home spaces - a 'tea party' in celebration of the beginnings of Jane's gender transition and a materialising of queerness through ' $\mathrm{T}$ ' party gatherings and objects, furnishings and décor that murky gendered norms.

In Andrucki and Kaplan's (2018) work in the U.S., they stress how 'homonormativity' (communicated through topics like marriage rights) regularly inflects the construction of different queer spaces. However, they also suggest most research still overwhelmingly centres on public spaces such as bathrooms (Doan, 2007; 2010). Singh et al. (2013) question how 'the gaze' is felt by trans people and suggests this is crucial in tackling a painful erasure of trans lives that can occur in and through space. Some of their participants stressed a need to invoke invisibility, strategically, to lessen the impacts of transphobia on their lives. Where participants diverged from gendered norms, many felt hypervisible and under constant scrutiny. This often manifests as a feeling of observation, causing participants to monitor their own and others' reactions; a hypervigilance resulting in self scrutiny in efforts to sustain a 'coherent' gender-based narrative. These tensions on campus relate explicitly to the availability of our third space- those associated with teaching, learning and socialising.

\section{SPACES OF TEACHING, LEARNING AND SOCIALISING}

Experiencing invisibility in queer and/or trans communities because of stereotypes is common and can serve as a barrier to recognition which is then later felt as an erasure:

When I legally changed my name and I got a new card, some stuff is still wrong because they can't match up the system. So my email has still got the wrong initials. And it's really frustrating because everybody knows how university emails are generated so I say what my name is and then people look at my email and go, "well, why is your email address different?" [...] And I see that every day and I'm like, that is a micro-aggression and it's something that I just have to kind of let go.

(Kurt, 24 year old trans male)

This article is protected by copyright. All rights reserved 
Kurt posits that disjointed systems and processes often curtail involvement in spaces such as convivial or activist groups, academic networks, conferences and other events. Administrative support for students can authorise a change of email for a student undergoing a gender transition but the design of digital infrastructures on campus means that the deadname of people who have transitioned often appears on digital networks. This is a bigger issue of the sex/gender logic that structures most computing algorithms rather than a challenge specific to the campus per se but Kurt suggested this is a micro-aggression that impacts wellbeing (Bivens, 2017). Storrie and Rohleder (2018) suggest similar, contending that the repeated mention of a deadname can convey hostility whilst perpetuating heteronormativity; combining into an oppression damaging to both physical and mental health. It is in such instances that LGBT groups have been underlined as crucial for the inclusion of trans people in campus culture.

Beyond the digital barriers to spaces of teaching, learning and socialising, participants felt that the existing LGBT network provides a welcoming space in which to converse with others. This network provides support, together with convivial space for the formation of friendship and/or sexual and romantic relationships. However, some postgraduates did not feel the LGBT network was as welcoming as it could be for trans people and saw the group as being of more benefit to younger undergraduates. Kurt explained that younger undergraduates tended to be more interested in frequenting the 'meat market of gay bars' rather than the alternative 'queer nights' he favoured. Blake makes a similar point:

I know there's the society [LGBT network] ... but I feel a bit awkward because I haven't been to any. So it might not be but it sounds forced. Like, it would be stilted. Like, "hi, you're another trans person and we have to be friends." So I don't know anyone else that's trans and I'd love to, but I don't really see anyone, raising any issues. Even within the society, on the Facebook page, it just seems to be like, "we've got this event." And that's it. No one's really talking about anything and you do feel quite alone I guess. [...] There isn't anything else and we have no talks and I feel every student here should have some kind of talk on pronouns. Y'know, in the introductory thing where they talk about meningitis and everything.

(Blake, 19 year old non-binary)

Blake highlights how a lack of visibility makes him feel 'alone' and 'invalidated', suggesting the university might change induction events and welcome materials to increase 
representation of trans, non-binary and those of other marginalised genders. An 'ally' programme may also be useful whilst other participants contended that seeing more LGBT 'successes' might improve their sense of belonging to - and thus, involvement in - teaching, learning and social spaces (see, also, Garvey and Drezner, 2013). Several people wished to draw attention to what they perceived as a lack of current provision on campus in these respects:

I guess that's the other thing. Boards that sort of have, say, the university newsfeed that no one reads [permanent digital displays on campus]. That's all very... sort of... straight and sanitised. So when it's LGBT history month, they don't even put that up on the board or if its Black history month, they also don't put it up there on the screens that flash news. I'm like, that's a really simple thing that you could do. Have as one of your six revolving news stories that nobody cares about... one of them being that. I'm not saying that people would necessarily read it but it would subtly be there all the time. Whereas instead, you get the banner [temporary laminated billboard poster] outside the Student Union that says, "LGBT history month" or 'Black history month".

(Kurt, 24 year old trans male)

Kurt was among the participants who argued that LGBT representation is currently restricted to a series of ad hoc events like Pride and 'LGBT history month', ignoring much queer news, events and information that could be showcased on a rolling basis.

In short, we see signs of trans students and staff attempting to get recognition for who they are on campus without exacerbating stereotypes, especially in relation to the body within different spaces of the campus that are discursively coded as binary male/female. Participants often discussed how this dilemma also has a community aspect as their image becomes - or does not become - part of what queer and/or trans people 'look like' and individual decisions become more politically fraught.

\section{CONCLUSIONS}

In this article, we have highlighted some of the ways that bathrooms, residential accommodation and spaces of learning and conviviality can produce interactions that silence, marginalise and exclude those who do not fit the male/female binary. Most of these interactions centre around presentation of the body, 'passing' and avoidance of hostility. The tyranny of gender bolsters norms and expectations of stereotypical male/female expression

This article is protected by copyright. All rights reserved 
that shape, and are shaped by, different places on campus. It is important to note that not all trans people have the same experiences. For example, staff, postgraduates, undergraduates, non-binary and binary trans people experience the campus in varied ways - and these experiences are made meaningful in and through place. Whilst our research has highlighted multiple challenges faced by trans students and staff, it is also important to recognise that these are not particular to HE but also taint urban spaces.

The micro-aggressions and misrecognition we describe highlight a need to reflect on available support channels for trans people specific to different campuses, student compositions and the institutional cultures that arise from these. Doan's (2010) tyranny of gender emphasises a shared struggle that impacts all people (cis and trans). Changes in and to taught content, improved name change processes and the tracking of gender transitions for both students and staff, as well as diversified recruitment, are all strategies that could support universities in building spaces welcoming of all genders.

\section{References}

Acciari, L. (2014). Education beyond the straight and narrow: LGBT students' experience in higher education. London: National Union of Students.

Ahmed, S. (2012). On being included: racism and diversity in institutional life. Durham, NC: Duke University Press.

Andersson, J., Sadgrove, J. and Valentine, G. (2012). Consuming campus: geographies of encounter at a British university. Social and Cultural Geography 13, 501-515. doi: 10.1080/14649365.2012.700725.

Andrucki, M. J. and Kaplan, D. J. (2018). Trans objects: materializing queer time in U.S. transmasculine homes. Gender, Place and Culture, 25, 781-798. doi: 10.1080/0966369X.2018.1457014.

Anthony, K. H. and Dufresne, M. (2007). Potty parity in perspective: gender and family issues in planning and designing public restrooms. Journal of Planning Literature 21 267-294. doi: 10.1177/0885412206295846.

Atkin, S., Barrett, C., Pavitt, C. and Thomas, S. (2016). Pride and prejudice in education: an exploration of experiences of sexual orientation and gender identity among postschool education learners and staff. National Union of Students and the Equality Challenge Unit. Available: http://www.nus.org.uk.

This article is protected by copyright. All rights reserved 
Bell, D. (1995). 'Perverse dynamics, sexual citizenship and the transformation of intimacy.' In D. Bell and G. Valentine (eds) Mapping Desire: Geographies of Sexualities. London: Routledge, pp. 304-317.

Bender-Baird, Kyla. (2016). "Peeing under surveillance": bathrooms, gender policing, and hate violence. Gender, Place \& Culture, 23, 983-988. doi:

10.1080/0966369X.2015.1073699.

Bivens, R. (2017). The gender binary will not be deprogrammed: ten years of coding gender on Facebook. New Media and Society, 19, 880-898. doi: 10.1177/1461444815621527.

Brown, G. (2012). Homonormativity: a metropolitan concept that denigrates "ordinary" gay lives. Journal of Homosexuality, 59, 1065-1072. doi: 10.1080/00918369.2012.699851.

Browne, K. (2006). A right geezer-bird (man-woman): the sites and sights of female embodiment. ACME: An International E-Journal for Critical Geographies, 5, 121143.

Browne, K. (2004). Genderism and the bathroom problem: (Re)materialising sexed sites, (re)creating sexed bodies. Gender, Place and Culture, 11, 331-346. doi: $10.1080 / 0966369042000258668$.

Cavanagh, S. L. (2011). You are where you urinate. Gay and Lesbian Review, 18, 18-20.

Cornwell, S. (2014). Recognising the full spectrum of gender? Transgender, intersex and the futures of feminist theology. Feminist Theology, 20, 236-241. doi: $10.1177 / 0966735012436895$.

Doan, P. (2016). To count or not to count: queering measurement and the transgender community. Women's Studies Quarterly, 44, 89-110.

Doan, P. (2010). The tyranny of gendered spaces - reflections from beyond the gender dichotomy. Gender, Place and Culture, 17 , 635-654. doi:

10.1080/0966369X.2010.503121

Doan, P. (2007). Queers in the American City: Transgendered perceptions of urban space. Gender, Place and Culture, 14, 57-74. doi: 10.1080/09663690601122309

Duggan, L. (2002). 'The new homonormativity: The sexual politics of neoliberalism.' In R. Castronovo and D. D. Nelson (eds.) Materializing Democracy: Toward a Revitalized Cultural Politics. Durham, NC: Duke University Press.

Ellis, S. J. (2008). Diversity and inclusivity at university: a survey of the experiences of lesbian, gay, bisexual and trans (LGBT) students in the UK. Higher Education, 57, 723-739. doi: 10.1007/s10734-008-9172-y.

This article is protected by copyright. All rights reserved 
Formby, E. (2015). \#FreshersToFinals: Understanding LGBT+ perspectives on, and experiences of, higher education. Sheffield: Centre for Education and Inclusion Research.

Foucault, M. (1977). Discipline and punish: the birth of the prison. Translated by Alan Sheridan. London: Penguin.

Fraser, N. (2000). Rethinking recognition. New Left Review 3, 107-120.

Garvey, J. C. and Drezner, N. D. (2013). Advancement staff and alumni advocates: cultivating LGBTQ alumni by promoting individual and community uplift. Journal of Diversity in Higher Education, 6, 199-218.

Herman, J. L. (2013). Gendered restrooms and minority stress: the public regulation of gender and its impacts on transgender people's lives. Journal of Public Management and Social Policy (Spring), 65-80.

Hines, S. (2010). 'Queerly situated? Exploring negotiations of trans queer subjectivities at work and within community spaces in the UK'. Gender, Place and Culture, 17, 597613. doi: 10.1080/0966369X.2010.503116.

Hines, S. (2006). "What's the difference?" Bringing particularity to queer studies of transgender. Journal of Gender Studies, 15, 49-66. doi: 10.1080/09589230500486918.

Hopkins, P. Botterill, K. Sanghera, G and Arshad, R. (2017). Encountering misrecognition: Being mistaken for eing Muslim, Annals of the American Association of Geographers 107, 934-948. doi: 10.1080/24694452.2016.1270192.

Jeffreys, S. (2014). The politics of the toilet: a feminist response to the campaign to 'degender' a women's space. Women's Studies International Forum 45, 42-51. doi: 10.1060/j.wsif.2014.05.003.

Johnston, L. (2018). Transforming gender, sex, place and space: geographies of gender variance. London and New York: Routledge.

Johnston, L. (2015). "Gender and sexuality I: Genderqueer geographies?" Progress in Human Geography. doi: 10.1177/0309132515592109.

Marsh, S., Mohdin, A. and McIntyre, N. (2019). Homophobic and transphobic hate crimes surge in England and Wales. The Guardian (14 June). Available: http://www.theguardian.com/world/2019/jun/14/homophobic-and-transphobic-hatecrimes-surge-in-england-and-wales.

Marine, S. B. and Nicolazzo, Z. (2014). Names that matter: exploring the tensions of campus LGBTQ centers and trans* inclusion. Journal of Diversity in Higher Education, 7, 265-281. doi: 10.1177/0886260517718543.

This article is protected by copyright. All rights reserved 
Mitchell, M. and Howarth, C. (2009). Trans research review. Manchester: Equality and Human Rights Commission.

Namaste, K. (2000). Invisible lives: the erasure of transsexual and transgendered people. Chicago, IL: University of Chicago Press.

Namaste, K. (1996). Gender bashing: sexuality, gender and the regulation of public space. Environment and Planning D: Society and Space, 14, 221-240. doi: 10.1068/d140221.

Nash, C. J. (2010). Trans geographies, embodiment and experience. Gender, Place and Culture, 17, 579-595. doi: 10.1080/0966369X.2010.503112.

Oswin, N. (2008). Critical geographies and the uses of sexuality: deconstructing queer space. Progress in Human Geography, 32, 89-103. doi: 10.1177/0309132507085213.

Overall, C. (2007). Public toilets: sex segregation revisited. Ethics and the Environment, 12, 71-91. doi: 10.2979/ETE.2007.12.2.71.

Penner, B. (2012). Queering bathrooms. Gender, Place and Culture, 19, 542-545. doi: 10.1080/0966369X.2012.693758.

Rosenberg, R. and Oswin, N. (2015). Trans embodiment in carceral space: hypermasculinity and the US prison industrial complex. Gender, Place and Culture, 22, 1269-1286. doi: 10.1080/0966369X.2014.969.685.

Singh, A. A., Meng, S. and Hansen, A. (2013). 'It's already hard enough being a student': developing affirming college environments for trans youth. Journal of LGBT Youth, 1, 208-223. doi: 10.1080/19361653.2013.800770.

Storrie, R. and Rohleder, P. (2018). 'I think if I had turned up sporting a beard and a dress then you get in trouble': experiences of transgender students at UK universities. Psychology and Sexuality. doi: 10.1080/19419899.2018.1492435.

Stryker, S. (2006). '(De)subjucated knowledge: An introduction to transgender studies.' In S. Stryker and S. Whittle (eds.) The transgender studies reader. New York, NY: Routledge, pp. 1-19.

Stryker, S. and Whittle, S. (2006). The transgender studies reader. New York, NY: Routledge.

Sue, D. W. (2010). Microaggressions in everyday life: race, gender and sexual orientation. Newark, NJ: John Wiley.

Ullman, J. (2018). Breaking out of the (anti)bullying "box": NYC educators discuss trans/gender diversity-inclusive policies and curriculum. Sex Education, 18, 495-510. doi: 10.1080/14681811.2018.1431881.

This article is protected by copyright. All rights reserved 
Waling, A. and Roffee, J. A. (2017). Knowing, performing and holding queerness: LGBTIQ+ student experiences in Australian tertiary education. Sex Education, 17, 302-318. doi: 10.1080/14681811.2017.1294535.

This article is protected by copyright. All rights reserved 